\title{
ALDIR BLANC, O GOLEIRO BARBOSA E O ARRASA-CURIÓ: UMA LEITURA DO FUTEBOL NA CRÔNICA "SINA"
}

Luis Eduardo Veloso Garcia*

RESUMO: Procuraremos neste artigo analisar o modo que o futebol pode ser interpretado dentro da crônica "Sina", presente no livro Brasil Passado a Sujo - A Trajetória de uma Porrada de Farsantes (1993), de Aldir Blanc. Através da crônica escolhida, explicitaremos como este esporte é retratado na obra do autor pela inserção de seus elementos míticos, mais precisamente neste texto pela trágica figura do goleiro Barbosa, e pela representatividade do futebol dentro de nosso cotidiano, a ta ponto de ser propulsor de diversos discursos referentes ao espaço do qual o autor faz parte, a Zona Norte do Rio de Janeiro demarcada pela Vila Isabel.

PALAVRAS-CHAVE: Aldir Blanc; Futebol; Crônica; Cotidiano. *dinhopiraju@gmail.com

Doutorando em Estudos Literários pela UNESP/ Araraquara, Mestre em Estudos Literários pela UEL, e Especialista em Estudos Linguisticos e Literários pela

ABSTRACT: This paper aims to analyze how the football can be interpreted in the chronicle "Sina", of the book Brasil Passado a Sujo - A Trajetória de uma Porrada de Farsantes (1993), by Aldir Blanc. Through of this chronicle selected, we will investigate as this sport is portrayed in work of the author by inserting their mythic elements, more precisely in this text by the tragic figure of goalkeeper Barbosa, and by the representativeness of football in our daily like of being propulsor of the several discourses concerning the local from which the author is part, the Zona Norte of Rio de Janeiro demarcated by Vila Isabel.

KEYWORDS: Aldir Blanc; Footballl; Chronicle; Daily. 
$\mathrm{O}$ artigo em questão objetiva traçar uma leitura do futebol dentro da crônica "Sina", do livro Brasil Passado a Sujo - A Trajetória de uma Porrada de Farsantes (1993), do escritor, compositor, poeta, romancista, historiador e até médico Aldir Blanc.

Através da interpretação da crônica, analisaremos o modo como este esporte é retratado na obra do autor pela inserção de seus elementos míticos e pela representatividade do futebol dentro de nosso cotidiano.

Interpretando as situações passadas pelo protagonista que ganhará a alcunha de Arrasa-Curió dentro do texto, iremos levantar um paralelo de sua figura com a representação trágica da qual o goleiro Barbosa está diretamente ligado por causa da função mítica construída em torno de seu nome.

Em relação aos elementos míticos, levaremos em consideração a maneira que o futebol concebe em sua visão popular uma significação para alguns jogadores, times ou jogadas que vão além do espaço restrito deste esporte, aceitando para si algumas noções que fazem parte da criação do mito.

Funções importantes do mito como a ressignificação no presente, sendo sempre explicado por uma ação que aconteceu no passado, mas que se desloca ganhando sentido também no presente, são bastante perceptíveis no esporte em questão, como poderemos ver no caso do goleiro Barbosa
- que será pormenorizado em nossa análise - que, ao levar os dois gols na maior tragédia do futebol brasileiro, a final da Copa do Mundo de 1950 no Maracanã, não só se tornou o responsável pela derrota, como diretamente virou o símbolo da tragédia.

Tal exemplo é constantemente lembrado quando um jogador da atualidade comete um erro tão trágico que pode colocar em risco sua carreira. É pela significação, então, no passado da "falha" e o peso que Barbosa carrega por culpa dela que a interpretação desse valor pode ser construída no presente.

Outro caráter do mito que participa desta ponte com o futebol é seu indiscutível valor como organizador de relações sociais, pois carrega e legitima alguns pensamentos gerais que formam uma unidade palpável na sociedade. Noções como a culpa podem ser mais bem entendidas pela referência a um mito como o de Édipo, assim como a noção de persistência por um Hércules e seus 12 trabalhos, entre tantas outras. $\mathrm{O}$ valor da tragédia e o sofrimento são entendidos perfeitamente por uma sociedade como a brasileira ao remeter à lembrança do já citado Barbosa.

O principal significado de um mito é, portanto, como nos diz Marilena Chauí no livro Convite a Filosofia (2004), conceber um modo de organizar a realidade por meio da atribuição de um sentido metafórico aos fatos e as coisas que nos 
cercam. Pelo mito também é possível criar relações das quais a sociabilidade se fortalece, com vínculos que facilitam a acomodação com o meio que vivemos, tornando o que poderia soar de difícil compreensão algo palpável por sua relação formalizada pela ordem do mito.

Por isso, questões como a permanência e ressignificações de um símbolo que confronta com a atemporalidade são as principais chaves de entendimento do mito, que nos discursos e espaços relacionados ao futebol encontram a vazão necessária em nossa sociedade, pois mais do que um esporte por aqui, é uma forma de identidade e compreensão nacional como veremos no decorrer do trabalho.

Tais elementos míticos presentes no cotidiano se apresentam na descrição do dia a dia do espaço urbano que a obra de Aldir Blanc se ocupa, demarcada pela linguagem, pelos hábitos, e, principalmente, pelas cenas que vão desde uma briga de casal até o mais abusado dos papos de boteco, respeitando sempre as especificidades daquele cotidiano retratado.

Por se preocupar com o retrato do cotidiano nacional, com o recorte específico para o espaço urbano do subúrbio carioca da Zona Norte, obviamente a obra de Aldir Blanc versará sobre o futebol, que é um elemento constituinte não só daquele espaço, mas de qualquer referência cotidiana dentro do nosso país.
Entre as falas que colaboram para a reflexão sobre o valor que este esporte adquire em nosso país, temos a apresentação do conhecido Dossiê sobre o futebol feito pela Revista USP, na qual o professor do departamento de sociologia da USP José Carlos Bruni reclama que o futebol, na simplificação de valores que aplicam a ele,

mal deixa entrever o universo de significações simbólicas, psíquicas, sociais, culturais, históricas, políticas e econômicas inesgotáveis que envolvem multidões, encontradas no público em geral, nas torcidas organizadas, nos jogadores e equipes técnicas e burocráticas, concentradas em torno de um espetáculo que empolga sociedades, nações, países, estados, em esfera planetária, mobilizando milhões de dólares conquistando a adesão cada vez maior de pessoas de todas as camadas sociais. ${ }^{1}$

Nessa impressionante gama de significações e espaços que o futebol atinge diretamente, com um peso ainda mais relevante no Brasil que tem suas bases de identidade e nacionalidade construídas em paralelo com uma porcentagem do ideal futebolístico, a intensa produção de discursos que ele gera compreende um alcance inimaginável na função de "complexo fenômeno de comunicação de massa”, como aponta o autor Marcelino Rodrigues da Silva, em sua dissertação intitulada "O Mundo do Futebol nas Crônicas de Nelson Rodrigues” (1997):
1. BRUNI. Revista USP: dossiê futebol, p. 7. 
2. SILVA. O mundo do futebol nas crônicas de Ne/son Rodrigues, p. 8.

3. SILVA. O mundo do futebol nas crônicas de Nelson Rodrigues, p. 9 os cantos e gritos de guerra das torcidas, as "conversas de botequim", o discurso verbal do jornalismo impresso, radiofônico e televisivo, a iconografia impressa dos jornais e revistas, o discurso imagético da televisão e do cinema, etc. Discursos que são produzidos e consumidos diariamente por um grande número de pessoas e que ocupam um espaço bastante significativo em nossa cultura. ${ }^{2}$

Para Marcelino (1997), esses discursos consumidos tão intensamente dentro do cotidiano nacional refletem num caráter semiótico que o futebol pode estabelecer, capaz de produzir sentidos variados "aos personagens, instituições e acontecimentos do universo futebolístico brasileiro", tornando-o um "sistema de significação extremamente dinâmico e especialmente relevante dentro do universo cultural brasileiro", entre os quais se pode destacar algumas representações como estas:

Os jogadores tornam-se grandes ídolos populares, encarnando desejos e aspirações da coletividade; os clubes se identificam com certas parcelas da população e passam a representá-las (os "times da elite", os "times da massa", os clubes ligados a colônias de imigrantes, etc); os jogos e campeonatos são tomados como representação de conflitos sociais; as histórias das vitórias nas competições internacionais se transformam em grandes épicas de exaltação da nação; etc. ${ }^{3}$
$\mathrm{Na}$ elaboração deste pensamento, o autor busca na introdução do livro Elementos de Semiologia (1993), de Roland Barthes, a sustentação da ideia de que "perceber o que significa uma substância é, fatalmente, recorrer ao recorte da língua" e que "sentido só existe quando denominado, e o mundo dos significados não é outro senão o da linguagem”. ${ }^{4}$ No caso do "recorte da língua" feito por Marcelino Rodrigues da Silva, o processo que ele abrange - "a análise do funcionamento do futebol como sistema de significação" - recorre aos "discursos que a sociedade produz a partir do jogo de futebol", especificamente na imprensa esportiva, que é "um lugar privilegiado para a produção e a cristalização dos sentidos que o imaginário social brasileiro atribui aos acontecimentos, personagens e instituições do mundo do futebol”. ${ }^{5}$

Em relação ao nosso trabalho, apontaremos este "recorte da língua" para o subúrbio carioca de Vila Isabel para compreender dentro de seus discursos tão bem alocados nos textos de Aldir Blanc o modo que o peso mítico de Barbosa é interpretado na crônica escolhida para a análise.

Por ser uma obra calcada no cotidiano urbano, especificamente de uma cidade de um país do qual o futebol é um elemento constituinte do dia a dia, os textos de Aldir Blanc trabalham com o futebol de diversas maneiras, desde seu uso como temática direta, ou de construção de frases que fazem parte deste universo futebolístico mas colocadas em outras
4. BARTHES. Elementos de semiologia, p. 12.

5. SILVA. O mundo do futebol nas crônicas de Nelson Rodrigues, p. 40. 
contextualizações, até as citações constantes de grandes personagens, jogadas e times que pertencem à mítica construída do imaginário futebolístico brasileiro.

Portanto, a produção de Aldir Blanc faz do futebol não só um tema recorrente capaz de convergir com o retrato do cotidiano urbano nacional, mas, acima de tudo, um elemento inerente do espaço que define sua obra.

No caso da crônica especificamente, então, temos um espaço capaz de refletir o cotidiano urbano de forma leve e natural, mas em nenhum momento supérfluo, como apontam todos os teóricos que escreveram sobre a crônica, definindo-a como o caminho da "cidade feita letra" - nas palavras de Eduardo Portella no ensaio "A Cidade e a Letra" (1958) como a chave do entendimento deste gênero.

A produção de Aldir Blanc em crônica, embora pouco estudada, é extensa, com mais de 30 anos de colaborações em diversos jornais do país, entre eles, o marcante início dentro do Pasquim, em 1975, as publicações nos veículos A Hora do Povo, Última Hora, Tribuna da Imprensa, Jornal do Brasil, $O$ Estado de São Paulo, O Dia, O Pasquim21 e O Globo, onde ainda escreve mensalmente; somando as contribuições para as revistas Bundas e Playboy; além de seus livros Rua dos Artista e Arredores (1978), Porta de Tinturaria (1981), Brasil Passado a Sujo - A Trajetória de uma Porrada de Farsantes (1993), Um
Cara Bacana na 19a (1996) e Rua dos Artistas e Transversais (2006), todos formados exclusivamente pela sua produção de cronista.

Entre as principais características do autor dentro do gênero, destacam-se a força eminente de um grande talento para retratar os tipos e a linguagem do subúrbio carioca, mais especificamente a Zona Norte do Rio de Janeiro, espaço no qual ele cresceu e ainda vive até hoje.

De texto coloquial e enxuto, a fala das ruas torna-se o elemento fundamental para a compreensão do trabalho de Aldir Blanc nas crônicas, cujas comparações com outros autores - entre eles Nelson Rodrigues, Sérgio Porto, Rubem Braga, e até João do Rio - acabam tornando-se naturais para alguns estudiosos.

Ao posicionarmos a crônica como a representação literária de nosso cotidiano, obviamente o futebol aparece com grande força, sendo ele um dos elementos constituintes do dia a dia brasileiro, seja nas conversas, nos meios de comunicação, ou mesmo na prática deste esporte.

Nas crônicas de Aldir Blanc, portanto, o futebol aparece com uma função primordial: representar, através dos seus elementos míticos - jogadores, jogadas ou jogos marcantes - e da linguagem pertencente a este esporte, outros níveis 
interpretativos dentro destas crônicas, nas quais o futebol se torna um interessante caminho para a compreensão.

Após esta explanação, entramos agora na análise pormenorizada da crônica "Sina", relativizando o modo que o elemento mítico referente ao goleiro Barbosa é explorado dentro do texto.

\section{"Sina"}

Na crônica "Sina", presente no livro Brasil Passado a Sujo - A Trajetória de uma Porrada de Farsantes (1993), o futebol cumpre um papel importante de socialização, sendo o meio que aproxima um personagem solitário que se sente deslocado, e que sonha ser aceito pelo espaço em que o futebol reina: as conversas de dentro dos butecos. Além disso, a compreensão de um sujeito trágico como o goleiro Barbosa - o único que até hoje é insistentemente lembrado pela derrota contra o Uruguai na final da Copa do Mundo de 1950, uma das datas mais tristes da história do nosso futebol - é um interessante paralelo com a construção do personagem do texto.

Na narração, temos então a história de um "sujeito grandalhão, desajeitado e com um nome desses que, embora simples, ninguém decora", rapaz este que vivia melindrado no bairro do Estácio onde morava, pois seu sonho era ser igua aos frequentadores dos butecos de lá, porém, totalmente inseguro e atrapalhado, achava isso uma tarefa impossivel de acontecer, isolando-se então em sua própria solidão, pois "tinha medo que descobrissem sua falta de assunto, seu permanente mal-estar diante das pessoas, seus gestos descontrolados que derrubavam jarros, derramavam copos e atingiam crianças".

No pensamento deste personagem, ele nunca alcançaria o status daqueles homens dos bares dos quais considerava, literalmente, seus heróis - verdadeiros ex-pracinhas sempre com alguma história das batalhas passadas prontas para serem contadas:

Pra ele, aqueles homens de cigarro no canto da boca sem queimar, de programa de corrida de cavalos nas mãos ágeis, dedos sujos de giz de sinuca, bigodes cuidadosamente aparados, de olhares ávidos e experientes pra bunda das mulheres - aqueles homens eram heróis. Sentia diante deles a mesma timidez, o mesmo constrangimento, a mesmo dor indecifrável que experimentara em sua cidade natal, ao ouvir as histórias do Seu Rocha, o ex-pracinha.

Nos butecos do Estácio todos eram, com certeza, ex-pracinhas. Só ele ainda não havia lutado sua grande guerra, só ele não tinha nada pra contar sobre as batalhas, só ele não havia feito as quase eternas camaradagens.

Outro grande medo do personagem, "muito pior do que se achar um merda" na frente dos heróis dos butecos, era "o ter-
6. BLANC. Brasil passado a sujo: trajetória de uma porrada de farsantes, p. 59

7. BLANC. Brasil passado a sujo: a trajetória de uma porrada de farsantes, p. 59. 
8. BLANC. Brasil passado a sujo: a trajetória de uma porrada de farsantes, p. 59.

9. BLANC. Brasil passado a sujo: a trajetória de uma porrada de farsantes, p. 60. ror do apelido" que ele poderia receber deles, "porque aqueles caras espertos, cheios de chinfra, mais cedo ou mais tarde iam botar nele um apelido devastador, asfixiante, mortal". ${ }^{8}$

Por tanta admiração, misturada com seu característico pânico, ele vivia nos "recantos escuros dos bares vazios, onde bebericava uma cerveja, a espreita de alguma sacanagem, ouvidos atentos às evasivas de duplo sentido, torturado pelos risos às suas costas" (Idem, ibidem, p. 60). Porém, um dia depois da "sexta cerva", ao ouvir uma frase sobre futebol, criou coragem e dirigiu a palavra àquela turma que tanto idolatrava, com ainda mais astúcia, pois foi através da correção de uma bobagem dita por um dos frequentadores do espaço:

- Valter Marciano foi dos nossos primeiros jogadores a brilhar na Itália.

Mancada é sempre comovente, ainda mais se o sujeito é vascaíno. Surpreso com a própria coragem, corrigiu o baixinho que chutara pra fora:

- Valter Marciano foi, de fato, um ídolo. Só que na Espanha. Morreu lá, num acidente de automóvel. ${ }^{9}$

Tamanho despautério de corrigir um daqueles heróis causou espanto entre eles, por isso, "um mulato de óculos escuros disse que tava certo e perguntou se ele lembrava a linha de 56". A resposta foi "na lata":

- Sabará, Livinho, Vavá, Válter e Pinga numa das últimas partidas, se não me engano. Sabará foi substituído por Lierte, com i. Não confundir com Laerte, que jogava no meio e era, por sua vez, substituído por Écio. Se não me engano. ${ }^{10}$

Pronto. Com uma resposta com tanta classe assim, o que parecia impossível aconteceu, recebendo "as homenagens a que boa memória tem direito: tira de queijinho, essa eu pago, também aprecia um rabo empinado?” (BLANC, 1993, p. 60). Tanto sucesso fez na mesa do buteco por causa da paixão - e memória - futebolística que acabou sendo convidado para uma seresta na casa do Paulo Amarelo, uma honra gigantesca para ele: "O Amarelo é um mito. Amigo do Amadeu, Tião da Garagem, Ceceu Rico, Hélio Barbeiro, Beijo Louco...”." Na seresta, quando achou que o medo ia atrapalhá-lo, enganou-se, e fez muito sucesso:

Tentou ficar atrás de uma goiabeira no quintal do pagode, mas foi saudado com grandes berros de "chega prá cá e junta-te aos bons”. Quase chorou. Os primeiros copos deram uma força. Acabou cantando aquela, "Dentro d'alma dolorida trago um riso teu...”. A moça de olhos claros deixou cair o lenço. Um coroa resmungou: "Esse grandão é dos meus".
10. BLANC. Brasil passado a sujo: a trajetória de uma porrada de farsantes, p. 60.

11. BLANC. Brasil passado a sujo: a trajetória de uma porrada de farsantes, p. 60.
EM TESE

BELO HORIZONTE

v. 20

N. 1

JAN.-ABR. 2014

GARCIA. Aldir Banc, o goleiro Barbosa e o Arrasa-Curió [...]

P. $12-24$ 
12. BLANC. Brasil passado a sujo: a trajetória de uma porrada de farsantes, p. 60.

13. BLANC. Brasil passado a sujo: a trajetória de uma porrada de farsantes, p. 61

14. BLANC. Brasil passado a sujo: a trajetória de uma porrada de farsantes, p. 61.
A noite era uma criança e ele reinava. ${ }^{12}$

discursos compartilhados no dia a dia, encontra no espaço do bar um dos locais para a disseminação desses discursos.

Porém, a seresta guardava um momento especial e decisivo para o personagem central desta crônica: o batismo, a escolha de seu apelido definitivo.

O baixinho do buteco pediu:

- Conta aquela defesa do Barbosa!

A catástrofe. Em plena ponte dos grandes braços pro canto esquerdo da meta, o safanão na gaiola do curió. O passarinho morto. A consternação do dono da casa.

Amadeu tacou-lhe um generoso cacete nas costas:

- Fica assim não. Isso acontece. Aí, minha gente, tristezas não pagam dívidas! Passemos à próxima atração! A seguir, ouviremos "Chão de Estrelas" na voz do nosso Arrasa-Curió. ${ }^{13}$

Depois da imitação do trágico goleiro Barbosa com o final trágico do pobre curió, o rapaz finalmente ganhava o temido - e divertido, neste caso - apelido. "O apelido. Para sempre”. ${ }^{14}$ O Arrasa-Curió

Como pode-se perceber neste resumo da crônica, o futebol acaba sendo o caminho possível para aproximar o ArrasaCurió dos seus heróis de buteco, e entre as causas possíveis para tal ocorrência, podemos elencar o alcance deste esporte em nosso cotidiano, que além de ser capaz de gerar inúmeros
O bar acaba representando um recorte interessante para compreender a dinâmica de interação que se estrutura no cotidiano, pois é perceptível na construção do personagem da crônica noções como a aceitação pelo grupo, o medo da rejeição naquele local, e, principalmente, a redenção construída pelo compartilhamento de um discurso em comum perante os indivíduos daquele determinado espaço.

A referência ao Barbosa pode ser interpretada na crônica como a concretização de um elemento mítico de nosso futebol, pois o drama de aceitação que o personagem atravessa constitui um paralelo interessante com a história do próprio goleiro, do qual Aldir Blanc sempre foi um dos maiores defensores e fãs.

Como já foi citado anteriormente, Barbosa é o goleiro da Seleção Brasileira que perde a final da Copa do Mundo de 1950 aqui no Brasil, no famoso Maracanazo, ${ }^{15}$ e o segundo gol em que o time do Uruguai vira a partida nos últimos minutos acaba por ser considerado uma grande falha sua, pois este deixa a bola passar através de um espaço mínimo entre ele a trave, estigmatizando a figura do goleiro, que sofrerá o peso de carregar toda a culpa daquela derrota eternamente.
15. Para entender melhor essa situação, recomenda-se a leitura de Maracanazo - Tragédias epopeias de um estádio com alma (2010), de Teixeira Heizer. 
16. Além da crônica citada, encontram-se também

referências a outras no artigo " $\mathrm{A}$

Memória do Trauma de 1950 no

de Elcio Loureiro Cornelsen.
A rejeição que Barbosa sofre é tão grande, que acabou se tornando um ótimo tema para os cronistas esportivos, pois a sua história sempre reaparece quando descrevem uma grande tragédia futebolística. Até mesmo Nelson Rodrigues deixou inúmeras crônicas sobre o goleiro ${ }^{16}$, e assim como faz Aldir, defende a importância do goleiro e define a real dimensão deste mito do nosso esporte como eterno:

Vejam 50. Quando se fala em 50, ninguém pensa num colapso geral, numa pane coletiva. Não. O sujeito pensa em Barbosa, o sujeito descarrega em Barbosa a responsabilidade maciça, compacta, da derrota.

O gol de Gigghia ficou gravado, como um frango eterno. O brasileiro já se esqueceu da febre amarela, da vacina obrigatória, da Espanhola, do assassinato de Pinheiro Machado. Mas o que ele não esquece, nem a tiro, é o chamado frango de Barbosa.

Qualquer um outro estaria morto, enterrado, com o seguinte epitáfio: - “Aqui jaz fulano, assassinado por um frango". Ora eu comecei a desconfiar da eternidade de Barbosa, quando ele sobreviveu a 50. Então, concluí de mim para mim: - "Esse camarada não morre mais!". Não morreu e pelo contrário: está cada vez mais vivo. ${ }^{17}$

A admiração que Aldir Blanc tem por Barbosa é tão grande que o goleiro é inclusive matéria de um dos textos que ele escreve sobre a história do seu time do coração no livro Vasco - a cruz do bacalhau (2009), que é intitulado de "Ícaro - Barbosa”, com a devida aproximação da trágica situação que o grande goleiro encarou a vida inteira com a mitológica história de Ícaro:

A história trabalha num espaço curvo de uma falta cobrada com estilo. Se o leitor perguntar, na mesa de "coroas" na qual meu pai bebe, do alto de seus 86 anos de vascaíno remido, no Momo, qual foi o maior goleiro que viram atuar, com as raríssimas exceções que cagam a regra, ouvirão em uníssono: Barbosa.

Barbosa, ao lado de Zico, foi a mais trágica figura do futebol brasileiro. Perderam um título em segundos. No caso de Barbosa, numa escapada de Ghiggia, que muitos atribuem à falha da defesa, Barbosa tomou o tal frango e viu todas as suas defesas miraculosas virarem pó. Revendo o lance, é muito difícil dizer que houve falha naquele chute cruzado. Antes ser conhecido por um pretenso frango imortal diante de 173.850 pessoas (público oficial) a marcar toca na várzea a vida inteira.

Em dois segundos vertiginosos, Barbosa experimentou a queda mitológica de Ícaro. Só que o goleiro, discreto e competente, não teve a vaidade de se aproximar do sol e sim de uma simples bola de couro que lhe queimou o voo. Mas há paradoxos nas lendas: à medida que o tempo passa, as asas 
18. BLANC. Vasco: a cruz do bacalhau, p. 143. queimadas de Barbosa adquirem a pátina dourada da história. Em outra versão do mito, Ícaro afogou-se quando buscava o pai e seu barco afundou. Parece coisa de português. Aqui também vemos o contrário funcionando: se aquela tarde fatídica pode ser considerada a data do naufrágio de Barbosa, a cada dia que passa, ele, atlântico, sai cada vez mais das profundezas para o sol generoso da posteridade. ${ }^{18}$

Com tanta tragédia acompanhando o nome do grande goleiro vascaíno, nada é mais significativo do que a imitação de uma defesa sua selar o que tanto temia o personagem da crônica, ganhando o apelido de Arrasa-Curió. É também na cena dessa tragédia que temos um dos pontos característicos do humor de Blanc dentro da crônica, que sempre beira o politicamente incorreto, pois este subverte a escolha do apelido que poderia soar como grande sofrimento em matéria de riso coletivo.

Ainda em relação ao elemento mítico referente ao futebol, a própria representação do goleiro dentro deste esporte acaba por representar um importante papel. Ricardo Silvestrin tem um poema que facilita compreender este valor mítico do goleiro:

o goleiro vê o jogo ao contrário o número um que ele carrega não é de primeiro, mas de solitário o gol que não houve, a bola na trave

ou presa entre as asas do seu vôo de ave

são pontos a mais no seu placar tonto

seu companheiro, o goleiro adversário

com quem trama o escore ideal:

zero a zero do começo ao final ${ }^{19}$

A figura do goleiro, como podemos perceber então no poema de Ricardo Silvestrin, sempre esteve ligada intimamente ao peso da tragédia, tanto pela solidão que faz parte da posição, quanto pela não aceitação de seus erros, pois um erro dele pode ser fatal para o time, diferentemente de um gol perdido por um atacante. Tão trágica é sua representação no futebol que até ouve-se em qualquer campo do país a famosa máxima que "onde o goleiro pisa não nasce grama".

Temos nesta crônica um personagem que nunca jogou no gol, mas que simboliza as principais características míticas desta posição, como a enorme solidão que demonstra, além de seu apelido vir do mais trágico de todos os goleiros, o injustiçado Barbosa.

Na questão do isolamento, por exemplo, o passo dado pelo personagem através dos comentários feitos como profundo conhecedor deste esporte, além de tornar-se a vazão para 

a trajetória de uma porrada d farsantes, p. 59. que ele superasse a insegurança e timidez dentro do espaço do buteco ao lado de seus heróis, foi também responsável pela real aceitação dele como figura pertencente ao bairro em que se passa a crônica - a Vila Isabel.

É no convite para a seresta na casa do Paulo Amarelo que a aceitação perante o bairro se concretiza, pois a sociabilização com figuras que não fazem parte somente do buteco e, até mesmo, o apelido ganho após o acidente, tornam-se um modo dele reafirmar sua identidade junto com os outros moradores daquele ambiente.

Sobre o humor tão característico do autor dentro do gênero, é interessante ressaltar como Aldir Blanc consegue transformar a situação do "batismo" de Arrasa-Curió, em que poderia soar extremamente trágica por causa do medo do personagem, numa divertida passagem da qual o apelido temido não aparece de forma ofensiva, mas sim como uma brincadeira leve que muda o peso da significação.

O apelido Arrasa-Curió, na verdade, faz com que a aparente tragédia do personagem torne-se uma história da qual o bairro sempre irá se divertir ao lembrar-se dela. É também o passo definitivo da aceitação da figura antes isolada, além de ser o desfecho humorístico ideal que tanto preza este modelo de texto que é a crônica.
Destaca-se também a construção da linguagem no texto pelo autor, sabendo colocar em prática o modo de falar daquele local, tanto dos homens do bar quanto do pessoal que participa da seresta do Paulo Amarelo. A própria descrição destes espaços pelo narrador em primeira pessoa leva em consideração a voz de alguém que domina o modo de falar da Vila Isabel e seus arredores.

Outro ponto importante da crônica é a forma com que Aldir Blanc trabalha o peso do trágico inerente do cotidiano transformando desde uma descrição do pessoal do bar "aqueles homens de cigarro no canto da boca sem queimar, de programa de corrida de cavalos nas mãos ágeis, dedos sujos de giz de sinuca, bigodes cuidadosamente aparados, de olhares ávidos e experientes pra bunda das mulheres - aqueles homens eram heróis" ${ }^{\prime 2}$ - até o medo de receber um apelido - "devastador, asfixiante, mortal" ${ }^{1}$ - em tramas intensas das quais os conflitos do dia a dia ganham dimensões ainda maiores do que imaginadas.

Dentro desta crônica, portanto, o futebol assume dois papéis distintos, mas importantes para seu entendimento: no primeiro, a função de quebrar o isolamento do personagem, tornando-se um meio acolhedor através do compartilhamento de seus discursos em um dos espaços que mais os dissemina que é o bar; no segundo, através da imitação da defesa de Barbosa que sela o apelido Arrasa-Curió, a referência a
21. BLANC. Brasil passado a sujo: a trajetória de uma porrada de farsantes, p. 59 
um dos elementos míticos que melhor representa a rejeição em nosso país, e o caminho da saída humorística tão necessária para este gênero capaz de transformar a temida rejeição em acolhimento do bairro.

\section{CONCLUSÃO}

Interpretar o futebol através do relato de Blanc é compreender um pouco mais da dinâmica da Zona Norte do Rio de Janeiro da qual ele cresceu, pois tais elementos míticos inerentes deste esporte e todos os discursos gerados por sua linguagem ocorriam de modo natural naquele espaço retratado no texto, e, obviamente, ocorrem ainda hoje em qualquer recorte feito no cotidiano nacional, afinal, estamos falando do esporte de presença mais imponente em nossa cultura.

$\mathrm{Na}$ crônica escolhida, vimos o futebol completando a leitura do paralelo entre o trágico goleiro Barbosa com o personagem Arrasa Curió, leitura esta que colaborou também para se criar uma interpretação do modo como essa posição é compreendida em campo.

Portanto, ao considerarmos as interpretações geradas pelo mundo futebolístico dentro da crônica analisada de Aldir Blanc conseguimos não só reafirmar a proximidade deste esporte com nosso cotidiano, mas compreender também o modo que um gênero tão presente em nosso dia a dia como a crônica é capaz de retratar este espaço.

No miúdo do cotidiano brasileiro que o futebol se mostra forte e presente, a tal ponto de não capitalizarmos a quantia de discursos gerados por esta prática. Aldir Blanc, mesmo que até de certo modo inconsciente, soube retratar essa prática e sua linguagem dentro da própria obra permeada pelo principal intuito de retratar a Zona Norte do Rio de Janeiro.

\section{REFERÊNCIAS}

BARTHES, Roland. Elementos de semiologia. São Paulo: Cultrix 1993

BLANC, Aldir. "Sina". In Brasil passado a sujo: a trajetória de uma porrada de farsantes. São Paulo: Geração, 1993, p. $59-61$

BLANC, Aldir. Vasco: a cruz do bacalhau. Rio de Janeiro: Ediouro, 2009

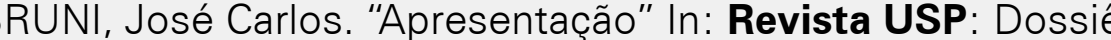
utebol. Número 22, 1994, p. 6-9.

CHAUÍ, Marilena. Convite a filosofia. São Paulo: Ática, 2004.

CORNELSEN, Elcio Loureiro. A memória do trauma de 1950 no testemunho do goleiro Barbosa. In: UFRJ, XI Encontro Nacional de História Oral, 2012, Rio de Janeiro. Memória, Democracia e Justiça. Simpósio: UFRJ, 2012. 
HEIZER, Teixeira. Maracanazo (tragédias e epopeias de um

estádio com alma). Rio de Janeiro: Mauad, 2010.

PORTELLA, Eduardo. "A cidade e a letra". In: Dimensões I. Rio de Janeiro: José Olympio, 1958

RODRIGUES, Nelson. A pátria em chuteiras. São Paulo: Companhia das Letras, 1994.

SILVA, Marcelino Rodrigues da. O mundo do futebol nas crônicas de Nelson Rodrigues. Dissertação (Mestrado em Letras), UFMG, Belo Horizonte, 1997.

SILVESTRIN, Ricardo. Quase eu. Porto Alegre: Coleção Peti Poa, SMC/Poa, 1992. 